\title{
Primary pancreatic lymphoma: endoscopic ultra- sound-guided Trucut biopsy to the rescue!
}

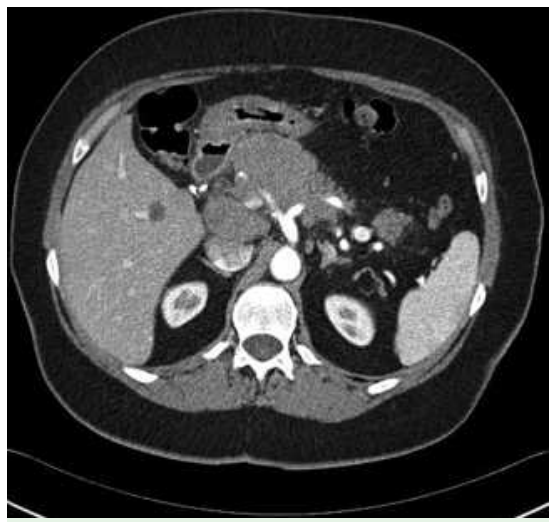

Fig. 1 Biphasic abdominal computed tomographic images revealed a poorly defined mass at the junction of the body and the head of the pancreas that measured $4.5 \mathrm{~cm}$ in diameter, and an incidental hepatic cyst.

A 64-year-old diabetic woman presented with a 1-week history of abdominal pain and cholestatic jaundice. Her laboratory tests showed: leukocyte count $7.2 \times 10^{9} / \mathrm{L}$ (normal range $3.5-10.5 \times 10^{9} / \mathrm{L}$ ), total bilirubin $10.5 \mu \mathrm{g} / \mathrm{dL}(0.1-1.0 \mu \mathrm{g} / \mathrm{dL})$, aspartate aminotransferase (AST) $337 \mathrm{U} / \mathrm{L}$ $(12-31 \mathrm{U} / \mathrm{L})$, alanine aminotransferase (ALT) $624 \mathrm{U} / \mathrm{L}(9-29 \mathrm{U} / \mathrm{L})$, alkaline phosphatase $724 \mathrm{U} / \mathrm{L}$ (50-130 U/L), lipase 24 $\mathrm{U} / \mathrm{L}(10-73 \mathrm{U} / \mathrm{L}), \mathrm{CA} 19-928$ units/mL (<55 units/mL) and IgG4 $137 \mathrm{mg} / \mathrm{dL}(8-$ $140 \mathrm{mg} / \mathrm{dl}$ ). Abdominal computed tomography revealed a pancreatic head mass that was encasing the portal vein and common hepatic artery but sparing the superior mesenteric artery, with evidence of peripancreatic and portal lymphadenopathy; there was no evidence of hepatic or splenic involvement ( $\bullet$ Fig. 1). Her chest radiograph was normal. Endoscopic ultrasound (EUS) revealed a $4.3-\mathrm{cm}$, echo-poor pancreatic head mass and a 1.4-cm (short axis) peripancreatic lymph node ( Fig. 2,3). EUS-guided fine-needle aspiration (EUS-FNA) of the pancreatic head and of the peripancreatic lymph node was performed.

The patient was diagnosed with primary pancreatic lymphoma. EUS-FNA of the pancreatic mass revealed very unusual atypical large lymphocytes, an appearance suspicious of but not diagnostic for large B-cell lymphoma ( Fig. 4). A Trucut biopsy of a cytologically suspicious

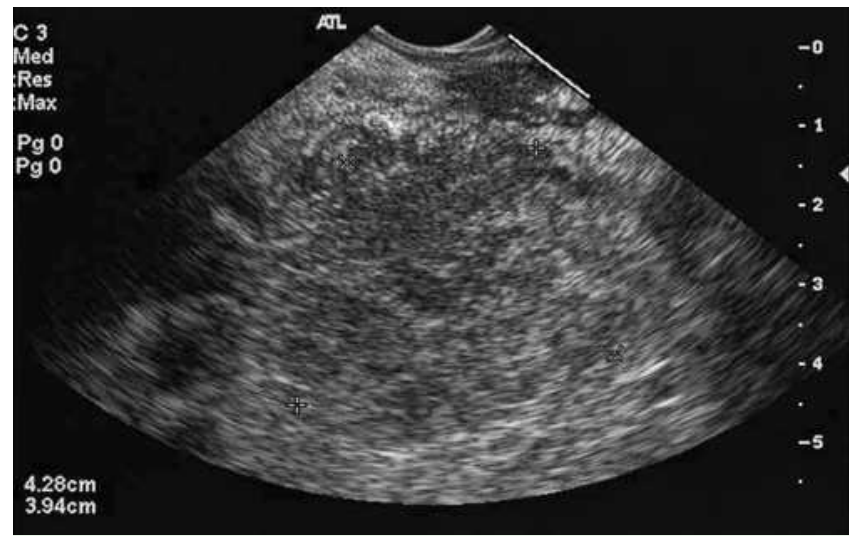

Fig. 2 Linear endoscopic ultrasound revealed a solid, echopoor mass involving the pancreatic head and body.

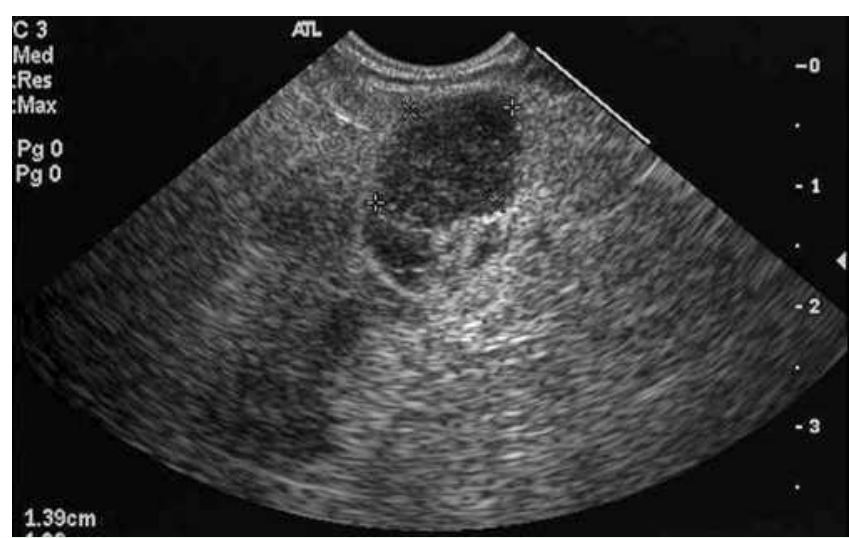

Fig. 3 Linear endoscopic ultrasound image of a large $(1.4 \mathrm{~cm})$ peripancreatic lymph node.

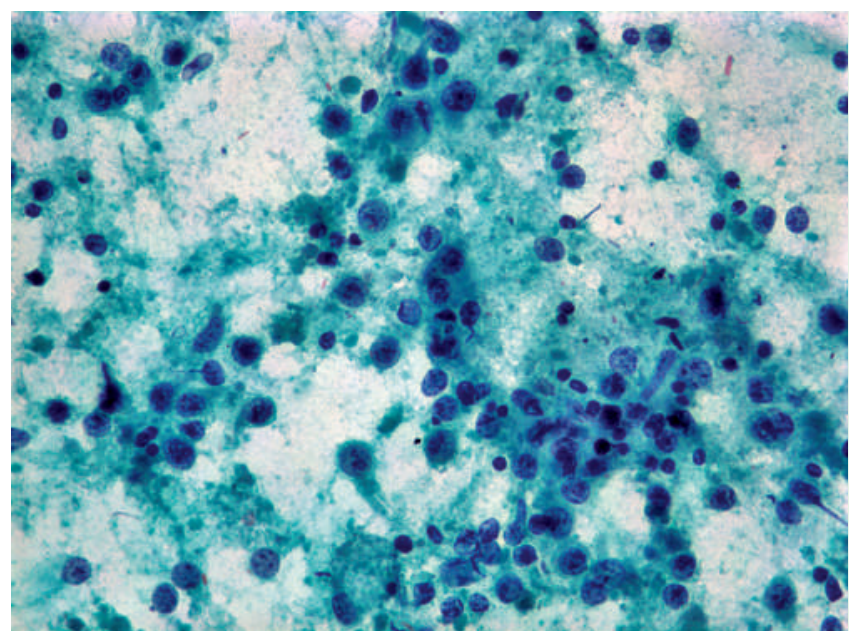

Fig. 4 A pancreatic fine-needle aspiration smear showing large, atypical, malignant lymphoid cells with scattered small lymphocytes (Papanicolaou stain, original magnification $\times 400$ ).

peripancreatic node confirmed the diagnosis ( Fig. 5). Immunoperoxidase studies of the Trucut biopsy tissue demonstrated large atypical lymphoid cells that were positive for CD45 and CD20 ( $\bullet$ Fig. 6). The patient's bone marrow examination was normal.

Primary pancreatic lymphoma accounts for less than $1 \%$ of extranodal non-Hodg- kin's lymphomas, of which $58 \%$ are of the large-cell type [1]. Diagnosis and subtyping can be achieved by EUS-FNA with adjuvant flow cytometry [2-4]. As EUS-FNA can fail to establish a definitive diagnosis of lymphoma, a Trucut biopsy can yield useful diagnostic and prognostic information, excluding carcinoma for example [5]. This case serves as a reminder that 


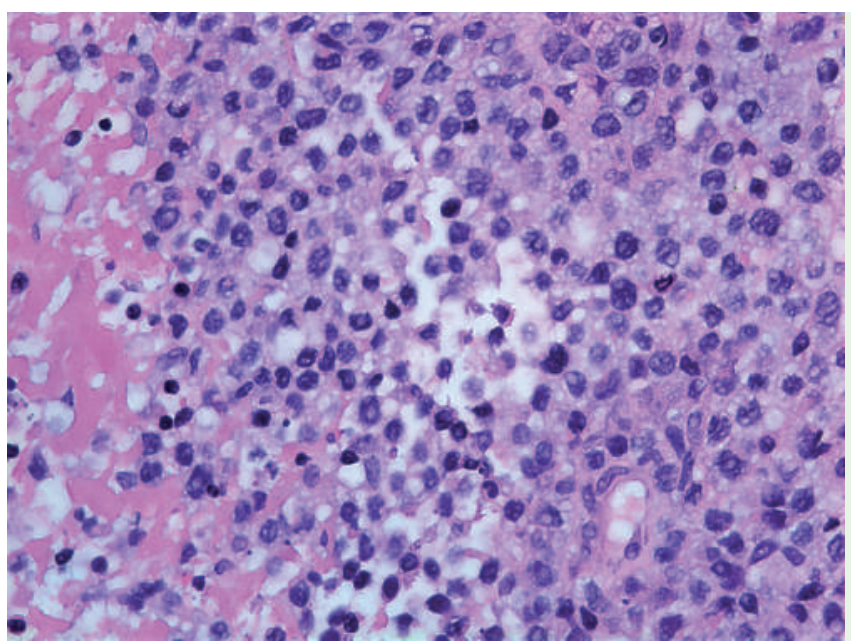

Fig. 5 Histological examination of the Trucut biopsy of the lymph node showed sheets of non-cohesive, large neoplastic cells with necrosis (on the left of the image) (hematoxylin and eosin stain, original magnification $x$ 400).

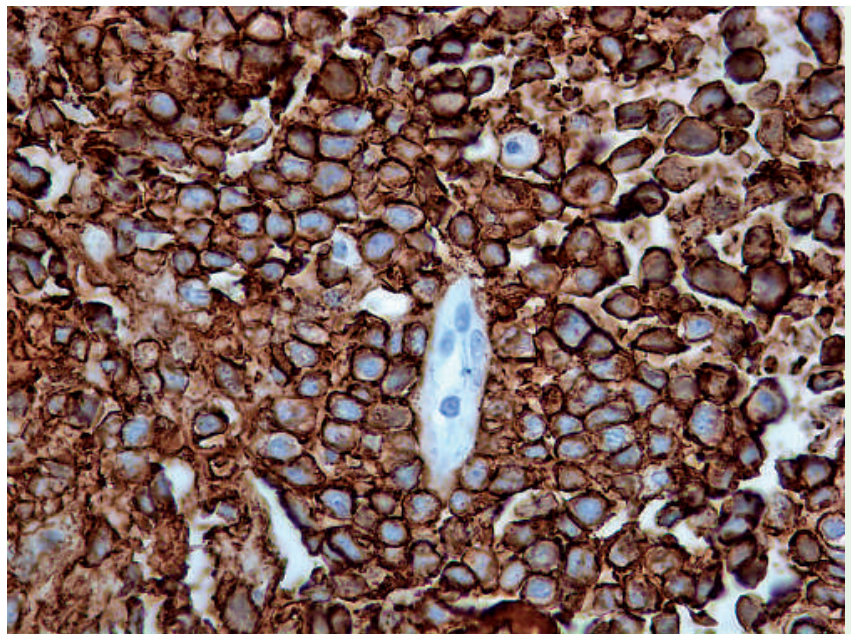

Fig. 6 Immunohistochemical staining showed the malignant cells to be positive for CD20 (original magnification $\times 400)$.

EUS Trucut biopsies can be useful as an adjunctive rescue technique when standard cytological techniques are inconclusive.

Endoscopy_UCTN_Code_CCL_1AF_2AZ_3AB

\section{F. C. Gleeson ${ }^{1}$, L. Zhang ${ }^{2}$, M. J. Levy ${ }^{1}$}

1 Division of Gastroenterology and Hepatology, Mayo Clinic College of Medicine, Rochester, Minnesota, USA

2 Department of Pathology, Mayo Clinic College of Medicine, Rochester, Minnesota, USA

\section{References}

1 Behrns KE, Sarr MG, Strickler JG. Pancreatic lymphoma: is it a surgical disease? Pancreas 1994; 9: 662-667

2 Saif MW. Primary pancreatic lymphomas. JOP 2006; 7: $262-273$

3 Volmar KE, Routbort MJ, Jones CK, Xie HB. Primary pancreatic lymphoma evaluated by fine-needle aspiration: findings in 14 cases. Am J Clin Pathol 2004; 121: 898 -903

4 Nayer $H$, Weir EG, Sheth S, Ali SZ. Primary pancreatic lymphomas: a cytopathologic analysis of a rare malignancy. Cancer 2004; 102: $315-321$

5 Gines A, Wiersema MJ, Clain JE et al. Prospective study of a Trucut needle for performing EUS-guided biopsy with EUS-guided FNA rescue. Gastrointest Endosc 2005; 62: $597-601$

Bibliography

DOI $10.1055 / \mathrm{s}-2007-966960$

Endoscopy 2008; 40: E23-E24

(c) Georg Thieme Verlag KG Stuttgart · New York . ISSN 0013-726X

\section{Corresponding author}

\section{J. Levy, MD}

Division of Gastroenterology and Hepatology Mayo Clinic College of Medicine 200 First Street SW, Charlton 8

Rochester

Minnesota 55905

USA

Fax: +1-507-266-3939

levy.michael@mayo.edu 